\title{
Analysis of GCMs for prediction of precipitation for Hoshangabad region of Madhya Pradesh
}

\author{
*ANKIT BALVANSHI and H. L. TIWARI \\ Department of Civil Engineering, Maulana Azad National Institute of Technology, Bhopal 462003, Madhya Pradesh \\ *Corresponding author Email: ankit19balvanshi@gmail.com
}

\begin{abstract}
Ten general circulation models (GCMs) - BCCR-BCCM2.0, Can-ESM2, CGCM3, CSIRO-Mk3.0, GFDL-CM2.0, GFDL-CM2.1, GISS, HADCM3, HADGEM1 and MIROC3.2 were analysed for prediction of precipitation for Hoshangabad region, Madhya Pradesh India. The performance indicator, skill score (SS),technique for order preference by similarity to an ideal solution (TOPSIS) techniques were employed for the selection of the best GCM. The multi-criterion decision making method (MCDM), technique TOPSIS was employed to evaluate and rank the $10 \mathrm{GCMs}$. On the basis of skill score and TOPSIS, GCMs CanESM2, CGCM3, GFDL2.0, HadCM3, MIROC3.2 is recommended for the study area. It is also found that GCMs CSIRO-Mk3.0 and GISS occupied the last two positions for Hoshangabad region, M.P., India.
\end{abstract}

Keywords: General circulation model, MCDM, precipitation, temperature, TOPSIS

General circulation models (GCMs) are numerical 3-d models which encompass the principles of fluiddynamics, thermo-dynamics and radiative heat transfer. The interactions of climate system are very complex so the GCMs are a helpful tool to develop relation/ equation for climate simulation (Anandhi and Nanjundiah, 2015). The GCM accuracy varies with region and type of parameter chosen for study; hence, GCM models are usually tested by finding their skill to simulate the "present climate" (Raju and Kumar, 2015). In climate change studies, daily precipitation is one of the most important parameter as it is responsible for runoff-generation, used in flood studies and also in planning and management of any water resources projects (Anandhi and Nanjundiah, 2015). Yadav et al. (2014) determined the trends of rainfall and temperature in districts of Uttarakhand using Mann-Kendall (MK) test and Sen's slope estimator. Climate change also creates an adverse effect on agriculture yield of crops thus GCM downscaling is necessary to reach to most precise prediction of climate (Patel et al. 2015). Das et al. (2016) conducted a research study to develop the temperature change scenarios over the Chilika Lagoon of India for 200 years (1901-2100). The study aimed to obtain better performing CMIP5 GCMs for the Chilika Lagoon and thereby computing the future temperature change using RCPs 2.5, 4.5 and 8.5. Akhter et al. (2017) tested the different CMIP5 models on the basis of spatial correlation (R), index of agreement (d-index), Nash-Sutcliffe efficiency (NSE), ratio of root mean square error to the standard deviation of the observations (RSR) and mean bias (MB) to generate the spatial rainfall patterns over seven homogeneous rainfall zones of India.

Due to the existence of uncertainties in GCMs, it is required for the selection of suitable GCM that can downscale climatic parameters with high accuracy. The main objective of this research work is aimed to obtain the best suitable GCMs, which can provide the best predictions of precipitation $\left(\mathrm{P}_{\mathrm{d}}\right)$ for the Hoshangabad region of Madhya Pradesh.

\section{MATERIALS AND METHODS}

The present study has been carried out for the Hoshangabad district located $22.75^{\circ} \mathrm{N}$ latitudes $77.72^{\circ} \mathrm{E}$ longitudes, on the southern bank of Narmada basin. The agriculture in this region is mainly dependent upon the precipitation received as the discharge in the Narmada river gets diminished during summers and after the monsoon period. One major impact of future climate change is changes in the region's water availability. Hence for the preparation of proper planning and adaptation policies to adapt with the changing climate, climate studies are crucially important.

The GCMs constitutes the climate system in a simplified form and prove to be powerful tool in finding the impacts of climate change (Johnson and Sharma, 2009). For the conduct of this research, $10 \mathrm{GCMs}$ of different modelling groups (Table 1) are chosen from the CMIP3 \& CMIP5 database to check out the suitability and performance of these models in the Hoshangabad region. As the GCMs 
Table 1:General circulation models evaluated in this research study

\begin{tabular}{lllll}
\hline $\begin{array}{l}\text { S. No. } \\
\text { Name of }\end{array}$ & Grid size & $\begin{array}{l}\text { Number of } \\
\text { grid points } \\
\text { in area }\end{array}$ & Organization \\
\hline 1 & BCCR-BCCM 2.0 & $2.8 \times 2.8$ & 02 & Bjerknes Centre for Climate Research, Norway \\
2 & Can-ESM2 & $2.790 \times 2.812$ & 02 & Canadian Centre for Environment and Climate change, Canada \\
3 & CGCM3 & $1.121 \times 1.125$ & 02 & Canadian Centre for Climate Modeling and Analysis, Canada \\
4 & CSIRO-Mk3.0 & $1.865 \times 1.875$ & 02 & CSIRO Atmospheric Research, Australia \\
5 & GFDL-CM2.0 & $2.5 \times 2.0$ & 02 & Geophysical Fluid Dynamics Laboratory (GFDL) USA \\
6 & GFDL-CM2.1 & $2.022 \times 2.5$ & 02 & Geophysical Fluid Dynamics Laboratory (GFDL) USA \\
7 & GISS & $2 \times 2.5$ & 02 & Goddard Institute for Space Studies, USA \\
8 & HadGem1 & $1.25 \times 1.875$ & 02 & Met Office Hadley Centre, UK \\
9 & HadCM3 & $2.5 \times 3.75$ & 02 & Met Office Hadley Centre, UK \\
10 & MIROC 3.2 & $2.790 \times 2.812$ & 02 & Centre for Climate System Research/ National Institute for \\
& & & & Environmental Studies and Frontier Research Centre for \\
& & & & Global Change, Japan \\
\hline
\end{tabular}

employed in this work comprise of different grid resolutions (Table 1) and irregular placements, it was necessary to bring the grid size to a common resolution. Hence all the outputs of GCMs were interpolated to a common grid of $2.5^{\circ} \times 2.5^{\circ}$ horizontal resolution using the inverse square distance relationship (Johnson and Sharma, 2009).

\section{Skill Score (SS)}

The similarity between two probability density functions (PDFs) related to GCM-based simulation and observation was calculated. It measures the amount of overlap between GCM-based PDF and observed PDF(Raju \& Kumar, 2015).

$S S=\sum_{i=1}^{n} \min \left(f_{m} f_{o}\right)$

\section{TOPSIS}

TOPSIS is based on the principle that the chosen alternative should have the shortest distance from the ideal solution and furthest distance from the anti-ideal solution (Raju \& Kumar, 2015). The methodology of TOPSIS consists of the following:

1. Computation of separation measure $\mathrm{D}_{a}^{+}$of each alternative $a$ from the ideal solution, that is, Euclidean distance of each criterion from its ideal value, and summing these for all criteria $(j=1,2, \ldots . . J)$ for given alternative $a$, that is,

$D_{a}^{+}=\sqrt{\sum_{j=1}^{J}\left(w_{i} f_{i}(a)-w_{j} f_{j *}\right)^{2}}$ where $\mathrm{j}=1,2, \ldots \mathrm{J} ; \mathrm{f}_{\mathrm{i}}(\mathrm{a})=$ normalized value of criterion $\mathrm{j}$ for alternative $\mathrm{a} ; \mathrm{f}_{\mathrm{j}^{*}}=$ normalized ideal value of criterion $\mathrm{j}$; $\mathrm{w}_{\mathrm{j}}=$ weight assigned to the criterion $\mathrm{j}$.

2. Computation of separation measure $\mathrm{D}_{\mathrm{a}}$ - of each alternative $a$ from the anti-ideal solution, that is, Euclidean distance of each criterion from its anti-ideal value, and summing these for all criteria $(\mathrm{j}=1,2, \ldots \mathrm{J})$ for given alternative $a$, that is,

$$
D_{a}^{-}=\sqrt{\sum_{j=1}^{J}\left(w_{i} f_{i}(a)-w_{j} f_{j * *}\right)^{2}}
$$

where $\mathrm{f}_{\mathrm{j}}^{* *}=$ normalized anti-ideal value of criterion $\mathrm{j}$.

3. Computation of relative closeness $\mathrm{C}_{\mathrm{a}}$ of each alternative $a$ is

$C_{a}=\frac{D_{a}^{-}}{D_{a}^{-}+D_{a}^{+}}$

The alternatives are ranked based on the $\mathrm{C}_{\mathrm{a}}$ values. The higher the $\mathrm{C}_{\mathrm{a}}$ value, the better the alternative.

\section{RESULTS AND DISCUSSION}

The Multi-Criterion Decision Making method (MCDM), technique TOPSIS was employed to evaluate and rank the 10 GCMs- BCCR-BCCM2.0, Can-ESM2, CGCM3, CSIRO-Mk 3.0, GFDL2.0, GFDL2.1, GISS, HADCM3, HADGEM1 and MIROC3.2 The skill score (SS) and ranks of the ten GCMs for Hoshangabad region is depicted in Table 2. It is observed from Table 2 that for precipitation the minimum SS is 0.64 for HadGEM1 whereas the maximum is 
Table 2: Outcome of skill score (SS) for Hoshangabad region

\begin{tabular}{lllllll}
\hline S.No. & GCM & SS of $\mathrm{P}_{\mathrm{d}}$ & \multicolumn{3}{c}{ Analysis using TOPSIS } \\
\hline 1 & & & $\mathrm{D}_{\mathrm{a}}^{+}$ & $\mathrm{D}_{\mathrm{a}}^{-}$ & $\mathrm{C}_{\mathrm{a}}$ & Rank \\
\hline 2 & BCCR-BCCM2.0 & 0.750 & 0.289 & 0.241 & 0.454 & 6 \\
3 & Can-ESM2 & 0.829 & 0.241 & 0.300 & 0.554 & 1 \\
4 & CGCM3 & 0.819 & 0.221 & 0.239 & 0.519 & 2 \\
5 & CSIRO-Mk3.0 & 0.661 & 0.324 & 0.210 & 0.393 & 10 \\
6 & GFDL-CM2.0 & 0.823 & 0.252 & 0.271 & 0.517 & 3 \\
7 & GFDL-CM2.1 & 0.779 & 0.310 & 0.255 & 0.451 & 7 \\
8 & GISS & 0.685 & 0.304 & 0.212 & 0.410 & 9 \\
9 & HadCM3 & 0.801 & 0.249 & 0.254 & 0.505 & 4 \\
10 & HadGEM1 & 0.640 & 0.298 & 0.221 & 0.426 & 8 \\
\hline
\end{tabular}

0.82 for CanESM2/GFDL CM2.0.

The results obtained after applying the TOPSIS and ranks of the GCM's are depicted in Table 2. The highest $\mathrm{C}_{\mathrm{a}}$ value indicates the $1^{\text {st }}$ rank and lowest $\mathrm{C}_{\mathrm{a}}$ indicates the $10^{\text {th }}$ rank. It is clear from Table 2 that CanESM2, CGCM3 and GFDL CM2.0 are the top three ranked GCMs based on their $\mathrm{C}_{\mathrm{a}}$ values.

\section{CONCLUSION}

On the basis of skill score and TOPSIS, Can-ESM2, CGCM3, GFDL2.0, HadCM3 and MIROC3.2 are found to be suitable for downscaling the precipitation for Hoshangabad region. GCM CSIRO Mk3.0 and GISS obtained the last ranks upon applying the TOPSIS technique. Furthermore, the data forecasted using the top ranked GCMs can be used in various agricultural yield studies for proper planning and management purposes that will reduce the agricultural risks.

\section{REFERENCES}

Akhter, J., Das, L. and Deb, A. (2017), CMIP5 ensemble-based spatial rainfall projection over homogeneous zones of India, Climate Dynam., 49(5-6): 1885-1916.
Anandhi, A. and Nanjundiah, R.S. (2015), Performance evaluatioin of AR4 Climate Models in simulating daily precipitation over the Indian region using skill scores, Theor Appl Climatol., 119: 551-566.

Das, L., Dutta, M., Meher, J.K. andAkhter, J. (2016), Temperature Change Scenarios over the Chilika Lagoon of India during 1901-2100, J. Climate Change, 2(1): 1-14.

Johnson, F.M. and Sharma, A. (2009), Measurement of GCM skill in predicting variables relevant for hydro climatological assessments, J. Climate, (22):4373"4382.

Patel, H.R., Lunagaria, M.M., Karande, B.I., Yadav, S.B., Shah, A.V., Sood, V.K. and Pandey Vyas (2015), Climate change and its impact on major crops in Gujarat, $J$. Agrometeorol., 17(2): 190-193.

Raju, K.S. and Kumar, N. (2015), Ranking general circulation models for India using TOPSIS, J. Water Climate Change, 6(2): 288-299.

Yadav, R., Tripathi, S.K., Pranuthi and Dubey, S.K. (2014), Trend analysis by Mann-Kendall test for precipitation and temperature for thirteen districts of Uttarakhand, $J$. Agrometeorol., 12(2): 164-171. 